\title{
Strategy to design the sea-level monitoring networks for small tsunamigenic oceanic basins: the Western Mediterranean case
}

\author{
F. Schindelé ${ }^{1}$, A. Loevenbruck ${ }^{2}$, and H. Hébert ${ }^{2}$ \\ ${ }^{1}$ CEA/DASE, Service "Technologie de la Mesure dans la Géosphère", 91297 Arpajon Cedex, France \\ ${ }^{2}$ CEA/DASE, Laboratoire de Détection et de Géophysique, 91297 Arpajon Cedex, France
}

Received: 4 April 2008 - Revised: 28 August 2008 - Accepted: 28 August 2008 - Published: 17 September 2008

\begin{abstract}
The 26 December 2004 Indian Ocean tsunami triggered a number of international and national initiatives aimed at establishing modern, reliable and robust tsunami warning systems. In addition to the seismic network for initial warning, the main component of the monitoring system is the sea level network. Networks of coastal tide gages and tsunameters are implemented to detect the tsunami after the occurrence of a large earthquake, to confirm or refute the tsunami occurrence. Large oceans tsunami monitoring currently in place in the Pacific and in implementation in the Indian Ocean will be able to detect tsunamis in $1 \mathrm{~h}$. But due to the very short time of waves propagation, in general less than $1 \mathrm{~h}$, a tsunami monitoring system in a smaller basin requires a denser network located close to the seismic zones. A methodology is proposed based on the modeling of tsunami travel time and waveform, and on the estimation of the delay of transmission to design the location and the spacing of the stations. In the case of Western Mediterranean, we demonstrate that a network of around 17 coastal tide gages and 13 tsunameters located at $50 \mathrm{~km}$ along the shore is required to detect and measure nearly all tsunamis generated on the Northern coasts of Africa.
\end{abstract}

\section{Introduction}

Most of the sea basins can be affected by local tsunamis, whose damage is very restricted close to the source. But only the basins that are surrounded by seismic zones can be affected regionally, i.e. by tsunamis provoking damage at distances of one to several hundreds of kilometers from the source.

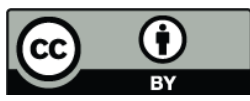

For the small sea basins where regional impacts are expected within the first hour after the source event, the need to detect as rapidly as possible the signal that could have been triggered or not is very crucial. Such an objective is very challenging for the western Mediterranean Sea where a Tsunami Warning System is under construction. This study seeks to understand, taking into account the seismicity of a specific small basin, how the tsunamis travel through this region, and where sea level sensors should be located to warn most efficiently the regions of an impending tsunami.

A comprehensive tsunami warning system is traditionally composed of a seismological network to detect earthquakes capable of generating a tsunami, and to determine source location and parameters. In addition, a coastal tide gage network is used to quickly confirm the existence or nonexistence of tsunami waves. These stations are located in the shallow water of harbors and bays where the tide measurement is required for navigation safety. Nevertheless in these environments tsunami waves are highly modified by linear and non-linear effects as they interact with the shoreline in shallow waters, thus the measurements often display the harbor resonances. In addition these sensors detect tsunami waves when they impact the harbors, and are useful only for other farther harbors or bays. Other data are needed to warn the same harbor well before the tsunami arrival.

A real-time deep ocean sea level network (tsunameters) completes the warning detection system for forecasting. The key feature of the tsunameter data is the rapid tsunami measurement, since tsunamis propagate with much greater speed in deep water. The corresponding tsunami record is not distorted by the non linear effects of shallow water. Another advantage to measure tsunamis in deep ocean is, for computational purposes, that the propagation may be approximated using simple linear theory.

The Pacific Tsunami Warning System (PTWS) utilizes a network of coastal tide gages and tsunameters (DART, Deepocean Assessment and Reporting of Tsunamis, and Japanese

Published by Copernicus Publications on behalf of the European Geosciences Union. 


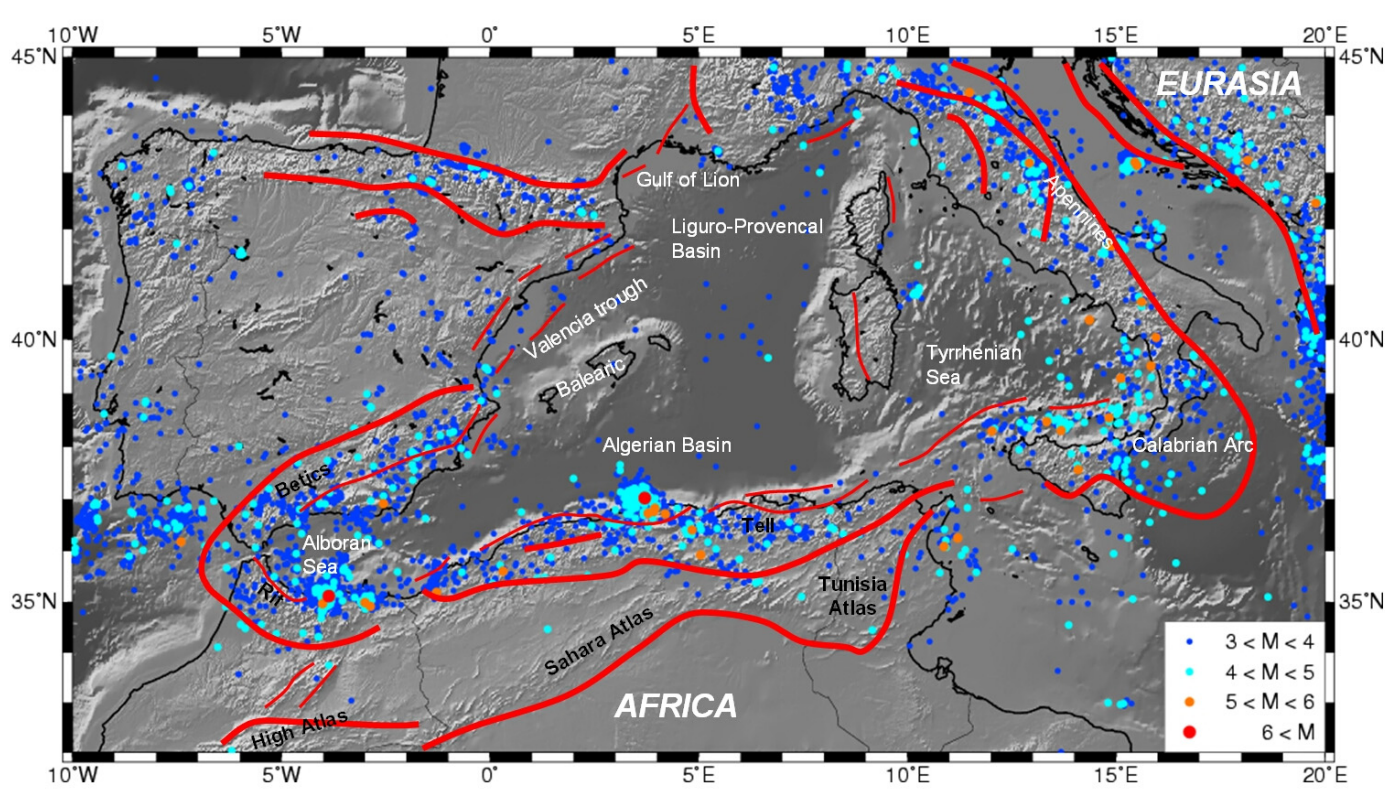

Fig. 1. Geodynamical map and recent seismicity of the studied region (adapted from Barrier et al., 2004 and Faccenna et al., 2004). Seismicity 1998-2005 courtesy of EMSC-CSEM.

cable stations). In that large ocean, out of the epicentral region, the coasts that are impacted by tsunamis are located far from the source at least $1000 \mathrm{~km}$ away, thus in general more than 5-6h of travel time. So, to contribute efficiently to the warning system, the spacing of the tide gages every $500 \mathrm{~km}$ along the coast, and the distance of $1000 \mathrm{~km}$ between the tsunameters and the coast provide sufficient time for forecasting, all the more as the source dimensions of most of the tsunamigenic events reach $200 \mathrm{~km}$ along the coast. Thus each tsunami can be recorded at least $1 \mathrm{~h}-1 \mathrm{~h} 1 / 2$ after the quake.

The goal of that study is to take into account the specificity of a small basin and to design the sea level network required for that basin. The case study is the south part of the Western Mediterranean, where historical and recent tsunamis already occurred. During history, some reports mentioned a significant tsunami generated by the destructive earthquake of Algiers in 1365 (Ibn Khaldoun, 1369). Recently, a strong tsunami affected the western Mediterranean following the 2003 Zemmouri earthquake (Mw 6.9) with significant damage mainly in the Balearic Islands (Alasset et al. 2006), and little damage on the French Riviera coast.

Eastwards, in 1856, a large earthquake also generated a tsunami that flooded Djidjelli and affected Balearic Island, in particular Mahon bay (Minorca) (Yelles-Chaouche, 1991; Harbi et al., 2003; Roger and Hébert, 2008).

In addition to those events, large earthquakes also occurred inland, large enough to generate a small tsunami that could be felt in some harbors. The El Asnam Mw 7.2 event in 1980 was located $60 \mathrm{~km}$ inland away from the coast, and has triggered a weak tsunami recorded in the South-Eastern coasts of Spain. Previously in September 1954, a destructive earthquake occurred in Orléansville, a few tens of kilome- ters northwards. Tsunami waves were clearly recorded in Alicante with maximum amplitude of $27 \mathrm{~cm}$ (Soloviev et al., 2000).

In response to the 2004 Indian Ocean disaster, the Intergovernmental Oceanographic Commission (IOC) of Unesco, decided to establish in June 2005 three additional Intergovernmental coordination groups for tsunami warning and mitigation systems, one for the Indian Ocean, one for the Caribbean and adjacent seas and one for the Northeast Atlantic, Mediterranean and connected seas. One of the major requirements is to design and implement a sea level network, efficient and adapted to specificities of each sub-basin.

\section{Western Mediterranean tsunamigenic potential}

Several recent studies suggested the tsunamigenic potential as an index considering the spatial frequency of tsunamigenic events and the geological and tectonic regime of the region (Henson et al. 2006). This approach that could be applied in such region as the Caribbean Sea, where more than 60 tsunamis occurred during the last 500 years, is not adequate to the Western Mediterranean region. In that region, very few detailed observations and evidences for large tsunamis suggest that specific historical and paleotsunami investigations must still be supported to build more comprehensive databases.

Nevertheless, seismotectonic studies of the Western Mediterranean (Fig. 1), submitted to the overall convergence between Africa and Eurasia, underline numerous active faults in northern Morocco, Algeria and Tunisia. Some of these structures extend offshore as revealed by recent marine investigations (Domzig et al., 2006), which possibly 
identified the segment related to the 2003 Zemmouri earthquake (Déverchère et al., 2005). Along the North Algeria coasts, numerous submarine fault segments have been interpreted as prone to generate large earthquakes that could trigger regional and basin wide tsunamis.

The design of the sea-level network built to monitor the Western Mediterranean region should take into account all the variability and location of the seismic sources.

In that region, most of the earthquakes magnitudes are small or moderate. None of them will generate directly a large tsunami similar to the transoceanic tsunamis generated at subduction zones. However the 2003 earthquake (Mw 6.9) reminds us of the possibility for magnitudes smaller than 7.0 to trigger significant tsunamis able to cause damage at distance. Even though the minimum magnitude threshold to trigger a tsunami is uneasy to identify, because it depends on several fault parameters, magnitudes down to 6.5 should not be discarded, depending on the fault conditions that must be studied in detail. Nevertheless, some of them could trigger landslides or rock failures that could induce a local tsunami.

Moreover, large earthquakes inland as the 1954 and 1980 events, could trigger weak regional tsunamis. The probability of these two categories of events is higher than the probability of large coastal earthquakes. But these events will not induce a significant deformation of the sea-floor, required for the tsunami generation on a regional scale. Consequently, the number of warnings related to those events should be as reduced as possible, meaning that the detection of corresponding tsunami waves must be as early as possible in order to cancel regional warning.

The coastlines most threatened by the waves of a specific tsunami are those located in the lobe of maximum tsunami energy, either in the epicentral area, or off the rupture zone at distance. To illustrate this affirmation, the case of the 2003 tsunami will be analyzed in detail, since the number of observations and records is higher than all previous events. Figure 2 displays the maximum water heights computed in Western Mediterranean for the 2003 tsunami. The map shows that the energy of the tsunami, at first order, is maximum in the direction perpendicular to the fault strike, as expected (Titov et al., 1999; Hébert et al., 2001). The almost nonexistent observations on the Algerian coast are probably due to the coseismic uplift, or to the steep submarine slopes which reflect most of the tsunami energy. But for that event, the largest amplitudes of the sea-level variations were observed in the Balearic Islands, located $350 \mathrm{~km}$ North of the epicenter, with a maximum of $2 \mathrm{~m}$ (peak-to-trough amplitude). In addition, local witnesses reported sea disturbances and damage to boats, some inundations and cars washed by the waves. Fortunately, this event occurred at night and not during the high tourism season. This event is a typical one for which a tsunami warning would be issued for the Algerian coasts around $400 \mathrm{~km}$ along the epicenter to the Balearic Islands, and a tsunami watch for the other coastlines of the rest of the basin.

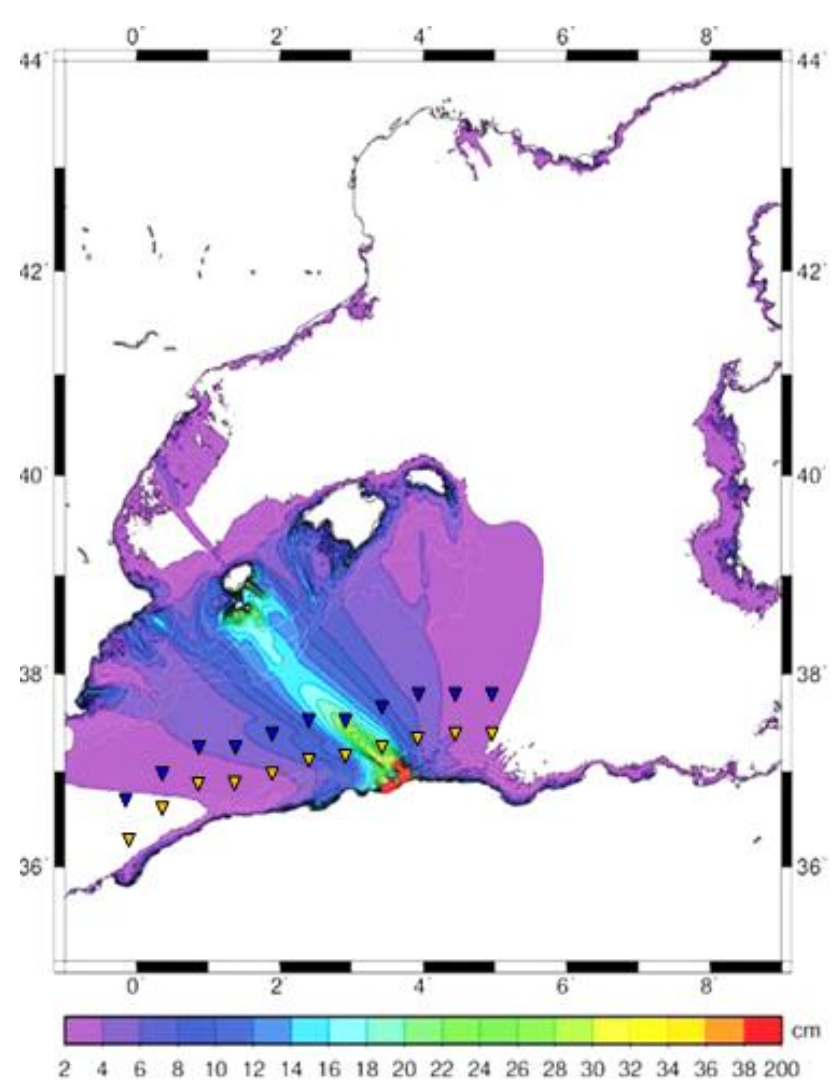

Fig. 2. Tsunameter networks 1 at $55 \mathrm{~km}$ offshore (yellow triangle) and 2 at $110 \mathrm{~km}$ offshore (blue triangle) superposed on the map of maximum tsunami height Induced by the 2003 Zemmouri earthquake. We can notice the directivity toward the Ibiza Island.

How could it be possible to detect in timely manner this tsunami to warn this region? As mentioned above, the only valid data able to provide a good estimation of the tsunami waves amplitude are the sea-level measurements. Over the last 20 years, some 10 sea level gage stations have been installed along Algerian, Morocco, Spanish, Tunisia and Sardinia coasts. As of July 2008, 3 stations are fully operational and transmitting data, 3 operational without any transmission and 5 new should be implemented. It must be noticed that today, no tsunameter is planned to be set up in that region.

\section{Methodology to design a sea level tsunami monitoring network}

The purpose of this paper is to design a tsunami warning system based on sea-level data records and processing capacities. The methodology is first to compute the minimum estimated time of arrival for the region that could be most affected by the tsunami, outside of the epicentral region. Then the second object is, considering a specific network spacing, to estimate the tsunami amplitude measurement. The finite difference numerical modeling is used to 
compute the tsunami propagation in deep sea. This model was successfully used for simulations of many recent and historical tsunamis (Alasset et al., 2006; Hébert et al., 2001, 2005; Sladen et al., 2007a, 2007b).

\subsection{The seismicity constraint}

As mentioned above, the only confirmation of the tsunami occurrence is given by the sea-level data, from tide gages and tsunameters. These networks must be designed to detect very early in the high risk regions. Consequently the number and spacing of the stations must be established in relation to the seismic activity.

\subsubsection{Low seismicity regions}

In all regions with no or very small seismic activity, the number of sea-level stations could be reduced to a minimum. In those areas, the only locations where a tide gage could be useful are the large harbors and marinas. In Western Mediterranean (Fig. 1), the Spanish coasts from Gibraltar to France and the French coasts of the Gulf of Lion are not prone to induce high local tsunamis. Along these coasts, the tide gages are essentially implemented to monitor the tsunami arrival and record the teletsunami waves signals. A $200-300 \mathrm{~km}$ spacing tide gage network would provide data to the regional warning system. The implementation of tsunameters along these coasts is not the priority.

\subsubsection{High seismicity regions}

The high seismicity regions are part of the most impacted by tsunamis. In all those regions, the sea-level network must be dense enough to detect a tsunami very early.

The impact on the coasts located close to the epicenter can not be forecasted by the tide gages data. At those coasts, the first tsunami wave will impact 5-20 minutes after the quake. Above all, educational activities must be encouraged in these epicentral areas where adequate reactions in the minutes following the earthquakes can save lives. In addition, as these sites are the most impacted by tsunamis, some actions can be taken to warn people and harbors farther along the coasts in order to limit damage to the boats and casualties.

\subsection{Delay of Detection estimation and network spacing}

\subsubsection{Tsunami travel time}

The tsunami travel time definition is provided in the IOC 2006 Tsunami Glossary: it is the time required for the first tsunami wave to propagate from its source to a given point on a coastline. This time is obtained from modeling of the tsunami by ray tracing as it travels from the source and is refracted due to bathymetry. The tsunami travel time is, in addition to the earthquake parameters, one of the main parameters required for a tsunami warning system.
The first application of the tsunami travel time was the publication of charts for warning centers. The first chart was made for Honolulu in 1947 by the American Coastal Service, after the disastrous 1946 Aleutian tsunami in the Pacific (Zetler, 1947). In 1971, the charts were reviewed and enlarged to about fifty charts used by the Tsunami Warning System (ANON, 1971).

During the eighties, the PTWS Member states expressed a strong need to publish new tsunami travel time maps. In 1984, IOC concluded an agreement with the Computing Center of the Siberian Branch of the USSR Academy of Sciences, to construct tsunami travel time charts for a number of locations of the Pacific coasts (Shokin et al., 1987). These charts were used by all warning centers to estimate the tsunami arrival time along their national coasts.

At the end of the eighties, studies were performed to compute tsunami travel time charts for other regions, in particular for the Caribbean. This program, originally designed for the Pacific coasts regions, has been adapted to generate charts for tsunamis in the Caribbean (Weissert, 1990). The results show that, from North to South of the Caribbean Sea, tsunamis travel in less than $1 \mathrm{~h} 1 / 2$ most of the coastlines being affected in less than $30 \mathrm{~min}$.

The tsunami travel time is the time required for the first tsunami wave (drop or rise) to propagate from its source to a given point on a coastline. This time is estimated from modeling the speed $\left(\mathrm{v}=(\mathrm{gh})^{1 / 2}\right)$ and refraction of the tsunami waves as they travel from the source. In the Western Mediterranean, the GEBCO map provides $1 \mathrm{~min}$ grid. As in this sea, the submarine slopes are generally very steep, the accuracy of the tsunami travel time is less than a few minutes.

Considering that this study is performed using point sources, and that, in reality, the seismic source length is greater than $30 \mathrm{~km}$ for magnitudes greater than 6.5 , the tsunami travel time estimation should be greater than the observed travel time.

Along the coastlines in front of the rupture zone, the travel time will vary from one source to another. For one specific epicenter, the minimum of tsunami travel time along the faced coastal zone can be computed.

The whole North African coast was considered as a continuous seismic region, consistently with the mean seismicity rate and the tectonics of the area (Fig. 1). This approach means that an earthquake may occur everywhere along the area, but it does not provide any probability or recurrence interval for the events. Besides, further studies of the margin are required to detail the seismotectonics of active faults off Morocco, Algeria and Tunisia. A total of sixteen epicenter points were modeled here (Fig. 3), evenly spaced every $1^{\circ}$ in longitude. They are only indicative for possible epicentral areas, but are not representative of specific events. Along the Spanish and Sardinia coasts, 15 forecast points are considered, distant from each other of $1^{\circ}$ in maximum.

The Fig. 4 represents for each of the 16 point sources along the North-Africa shoreline, the computed arrival times 


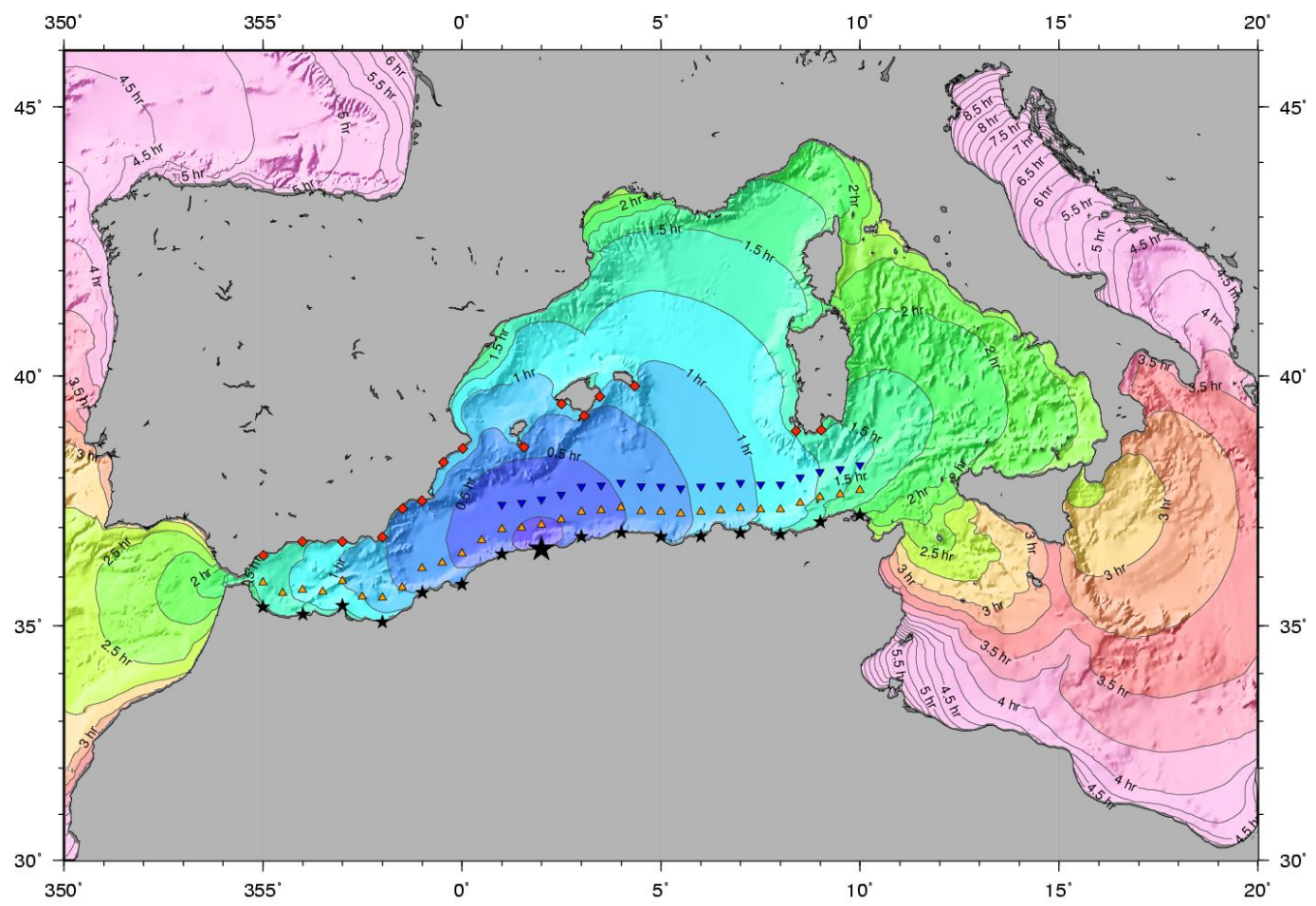

Fig. 3. Tsunami travel time chart for the event $n^{\circ} 8$ (located longitude 2.0). Black stars are the location of the 16 sources, Yellow triangles is the tsunameter1 Network located $55 \mathrm{~km}$ offshore, Blue triangles is the tsunameter 2 network located $110 \mathrm{~km}$ offshore and red dots are the site locations in Spain and Sardinia for the closest area.

mboxestimated at all the 16 sites. The tsunami arrival times vary along the African coasts from a few minutes for the closest tide gage to $3 \mathrm{~h}$, with an average value of $75 \mathrm{~min}$.

Two networks of tsunameters are envisaged and tested; tsunameter 1 and tsunameter2, respectively located $55 \mathrm{~km}$ and $110 \mathrm{~km}$ away Northern Africa shoreline. The Fig. 5 shows the minimum of travel time from each source to the forecast points and the delay between the arrival time on the Spanish coasts, the Balearic coasts or the Sardinia coasts and the arrival time at both tsunameters networks. For the tsunameter1 network, the minimum delays range from 15 to $36 \mathrm{~min}$. For the tsunameter 2 network, for the eastern part (longitude greater than 2 degrees), the minimum delays vary from 17 to $30 \mathrm{~min}$, in general $5 \mathrm{~min}$ shorter than for tsunameter1.

The awaited parameter during a tsunami warning is the estimated time of arrival (ETA) of the first tsunami waves, at locations along the coastlines. The ETA is estimated adding the tsunami travel time to the origin time of the earthquake. In case of possible tsunami in the Pacific Ocean, the PTWS warning centers disseminate in their messages ETA at the forecast points.

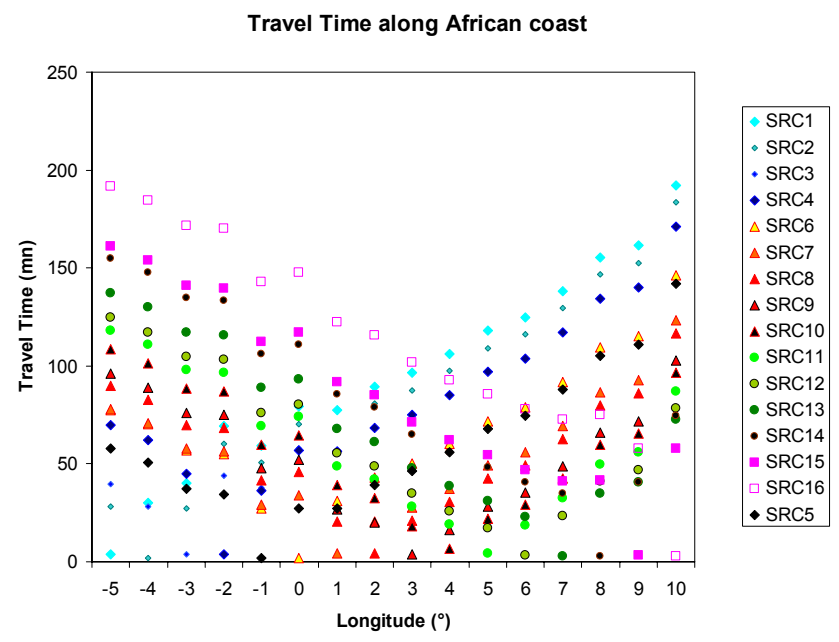

Fig. 4. Tsunami travel time along the African coast, for the 16 events spaced every $1^{\circ}$. (Source 1 SRC1 at $5^{\circ} \mathrm{W}$ to Source 16 $\mathrm{SRC} 16$ at $\left.10^{\circ} \mathrm{E}\right)$

\subsubsection{Tsunami amplitude measurement}

The tsunami amplitude must be measured on the sea level record. It is intended to represent the true amplitude of the tsunami wave in some point along the coast or in the ocean. 


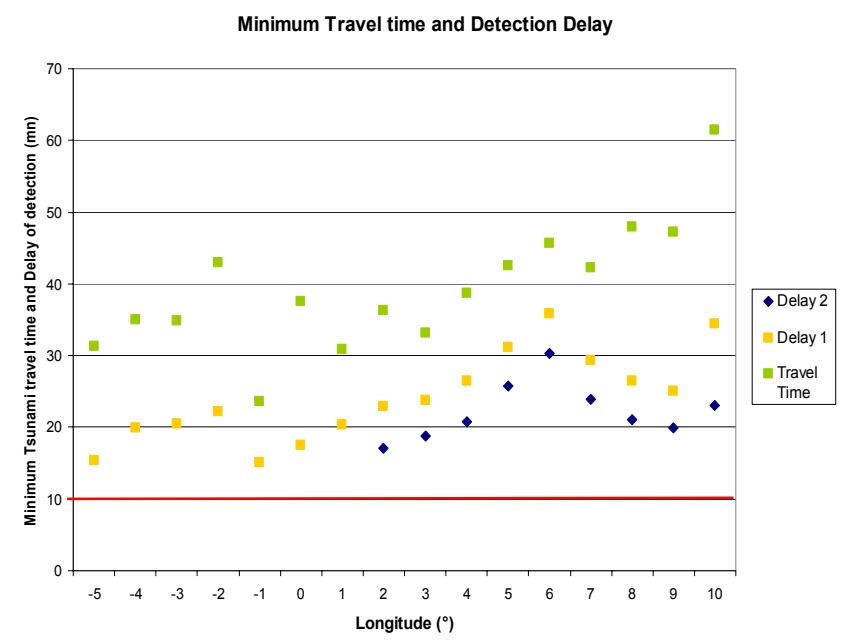

Fig. 5. Minimum tsunami travel time from West (left) to East (right) and related warning delay for the tsunameter1 (Delay1) and tsunameter2 networks (Delay2). The red line of 10 min represents the amplitude measurement and transmission delay.

The tsunami period, amount of time that a tsunami wave takes to complete a cycle, ranges from $5 \mathrm{~min}$ to one hour. Typically for earthquake-induced tsunamis, the dominant period is close to $20 \mathrm{~min}$. To measure the amplitude of the first peak (negative or positive), the required record length must be at least a quarter of a wave period, that is 6 to $8 \mathrm{~min}$ of signal. We use the recent DART record in the Indian Ocean of the February 25th, 2008 Sumatra tsunami (Fig. 6) as an example. The estimated time of arrival and the first extremum 6 min later are indicated.

In case of very large tsunami heights, a level of several tens of centimeters could be recorded in less than $5 \mathrm{~min}$. A threshold could be implemented to rapidly detect the largest tsunami waves, and for those events, to reduce the delay of detection. Nevertheless, in this study 8 minutes from the ETA are considered as the delay necessary for wave detection and amplitude measurement of any tsunami.

\subsubsection{Delay of transmission}

In the Pacific, the delay of transmission of the sea level data is $5 \mathrm{~min}$ or $15 \mathrm{~min}$, depending on the Global Telecommunication System (GTS) available satellite. This delay is short, in comparison with the teletsunami travel times. The GTS currently in place in the Mediterranean region allows to transmit the data from all remote sites without any local telecommunication link, but only every $15 \mathrm{~min}$. This delay is too long for such a small basin.

The Internet connection delay is in general faster than 12 min. This type of transmission is very useful in areas where there is no risk of local or national telecommunication failures. The limitation of this type of transmission is for regions prone to large disasters like earthquakes that could cut or saturate the connections during several hours. Consequently the

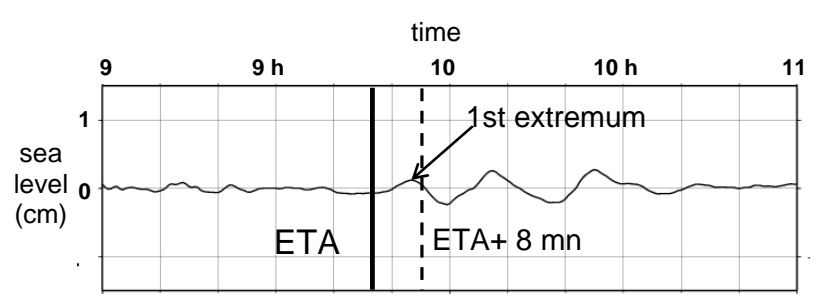

Fig. 6. Estimated Time of Arrival (ETA) and 1st extremum arrival on the DART Tsunami record in the Indian Ocean (Sumatra earthquake Mw 7.3 25 February 2008).

sea-level data of the tide gages located close to the epicenter, which are the most important measurement for the confirmation, may not be available during several hours.

A new transmission link is recently available: the Broadband Global Area Network (BGAN) which uses the Inmarsat satellites. This system, as the GTS transmission, has the benefit of an independent link of the local telecommunication system. The advantage in comparison with GTS is the small delay of transmission inferior to $2 \mathrm{~min}$.

For that study, we consider a 2 min transmission delay. Adding tsunami amplitude measurement and transmission delays, a total delay of $10 \mathrm{~min}$ must be substract to the tsunami travel time.

\subsubsection{Delay of detection}

The Fig. 5 shows that if a 10 min delay is considered for amplitude measurement and transmission, the minimum time for warning varies from $5 \mathrm{~min}$ in the worst scenarios to $25 \mathrm{~min}$. In the Alboran Sea, in the Western part of Mediterranean Sea, the minimum warning time varies from 5 to $10 \mathrm{~min}$, due to the small distance from Africa to Spain, in contrast with the region between Balearic and Sardinia islands where the delay varies from 15 to $25 \mathrm{~min}$.

$5 \mathrm{~min}$ is a very short time to evacuate people on a beach. One suggestion to increase this time could be to implement the tsunameter network closer to the shoreline. This is not feasible due to two constraints. The first one is that the pressure sensors must be located on a flat part of the sea floor; the required minimum distance from the shoreline in that region is greater than $40 \mathrm{~km}$. The second is the fact that the submarine slope is steep along the North African coasts; such slope is prone to submarine landslides (Alasset et al. 2006) that could destroy cables and pressure sensors. In that area the best and safe solution is to implement the DART stations around $50 \mathrm{~km}$ off the shoreline.

\subsubsection{Tsunameters network spacing}

The second parameter of the network is the tsunameters spacing range.

Tsunamis are highly directional, with a relatively narrow beam of focused energy. Consequently, the tsunami could 
propagate undetected through a network of too widely spaced tsunameters. Tsunameters spacing of about $200-400 \mathrm{~km}$ along the subduction zones is required to reliably assess the main energy beam of a tsunami generated by a M 8.0 earthquake (Gonzalez et al., 2005). The beam width decreases with rupture zone length and earthquake magnitude. The consequent requirement is that tsunameter spacing must be reduced in the same ratio.

In Western Mediterranean, the typical earthquake magnitude that could generate regional or basin wide tsunamis ranges from 6.7 to 7.3 . The average rupture length of those events varies from 50 to $90 \mathrm{~km}$.

To precisely analyze which spacing is appropriate to detect the tsunami and correctly estimate the amplitude, the Zemmouri 2003 event serves as case study. The beam width of that event is around $100 \mathrm{~km}$ (Fig. 2). The amplitude measurement, derived from modeling, is first performed $110 \mathrm{~km}$ away from the coast based on the tsunameter2 network, where no local effect could modify the beam. The maximum of amplitude at that distance is $18 \mathrm{~cm}$ (Fig. 7). A $45 \mathrm{~km}$ spacing network would record at least a $15 \mathrm{~cm}$ tsunami, since the beam width amounts to $120 \mathrm{~km}$. A $90 \mathrm{~km}$ spacing would record only a 11 to $18 \mathrm{~cm}$ amplitude, depending on the relative position of the beam within the network. In that case, a ratio 2 between the observed amplitude and the maximum amplitude could be expected, which is a relatively large value for any forecasting method.

The other option could be to locate the tsunameters closer to the coasts. At $55 \mathrm{~km}$, which corresponds to the tsunameter1 network, the beam width is quite equal to that at $110 \mathrm{~km}$. So, the spacing must be the same. The only difference is the increase of the maximum amplitude of the wave; $24 \mathrm{~cm}$ in the direction of the maximum of energy and $8 \mathrm{~cm}$ on the sides. The ratio is quite similar to the ratio at $110 \mathrm{~km}$.

The length of the tsunamigenic coasts from Gibraltar to Tunisia is approximately $1500 \mathrm{~km}$, so the sea level network requires 16 tsunameters with a $90 \mathrm{~km}$ spacing.

\section{Results and discussion}

All recent and historical large events suggest that the tsunami hazard exists in the Western Mediterranean Sea. The 1954 Orléansville and $1980 \mathrm{El}$ Asnam earthquakes located more than $40 \mathrm{~km}$ inland, induced small tsunamis recorded at Spanish tide gage stations (Soloviev et al., 2000). The recent Zemmouri M 6.9 earthquake generated a large tsunami: the wave amplitude and the tsunami impact on the Balearic islands were much larger than most of similar events with magnitude 7.0-7.5 on the Pacific subduction earthquakes. The main explanation is that the $45^{\circ}$ slope of the Zemmouri fault is very steep in comparison with the $6-15^{\circ}$ typical subduction zone dip angle. The consequence is that, considering the same dislocation amount, the vertical motion of the sea-floor could be 5 to 10 times larger, over a thrust fault such as the Zemmouri

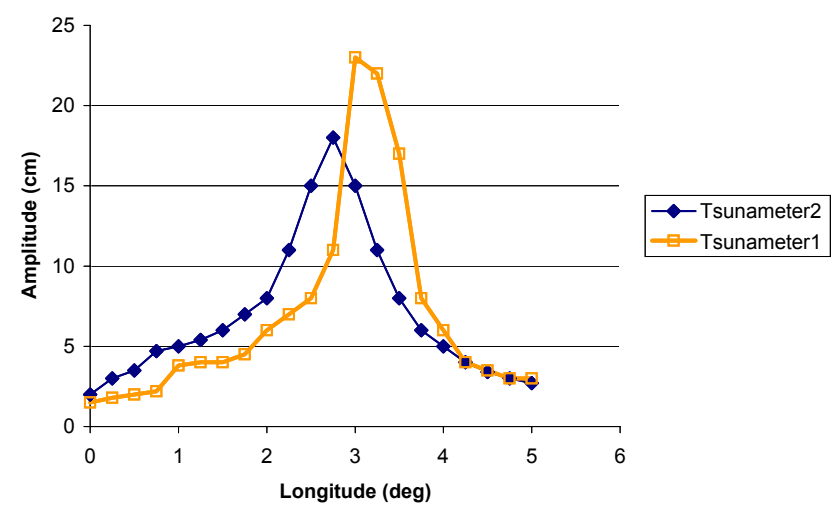

Fig. 7. Amplitude of the tsunami recorded by the closest tsunameter1 network (orange) and the tsunameter2 network located at $110 \mathrm{~km}$ offshore (blue) (see Fig. 2). A spacing of more than $90 \mathrm{~km}$ could detect a $6-8 \mathrm{~cm}$ tsunami, 3-4 times smaller than the maximum amplitude.

one. One of the consequences is that the magnitude warning threshold must be reduced in Western Mediterranean, a 6.5 value could be appropriate, whereas a 7.0 threshold is suitable in the Pacific and Indian Ocean.

The very recent 14 February 2008 M 6.9 Greek earthquake confirms that difference: the slope of the rupture zone of that earthquake was very flat around $6^{\circ}$ and no tsunami was observed or recorded on tide gages. In that area, the threshold of 7.0 used for typical subduction zone should be applied.

Considering the design of the network, one of the concerns is to reduce the number of tsunameters, without affecting the efficiency of the network. The return period of the large earthquakes is not very well known. The catalogue of earthquakes and tsunamis does not allow us to distinguish zones where large earthquakes are expected in the next decades from zones where large earthquakes are definitively not expected. In Western Mediterranean, the return period of the large earthquakes is certainly between a few hundred of years to thousand years.

The analysis of the vulnerability of the Western Mediterranean shorelines provides another point of view. In fact, along the Spanish and French coasts, the vulnerability changes drastically from one season to another and from night to day time. The number of people living and staying on beaches and in harbors is varying from thousands of people at night in winter to millions of people in summer during the day time.

It is recognized that the sea level networks are the only tools to forecast and save those people. The implementation of the tsunameter network must become a major priority of the tsunami warning system that must be built in Western Mediterranean, together with the awareness and preparation of populations. The tsunami signal in deep ocean is not perturbed by local coastal and harbor effects and this network will allow developing new forecast tools for tsunami warning and mitigation, based on numerical models and data bases. 


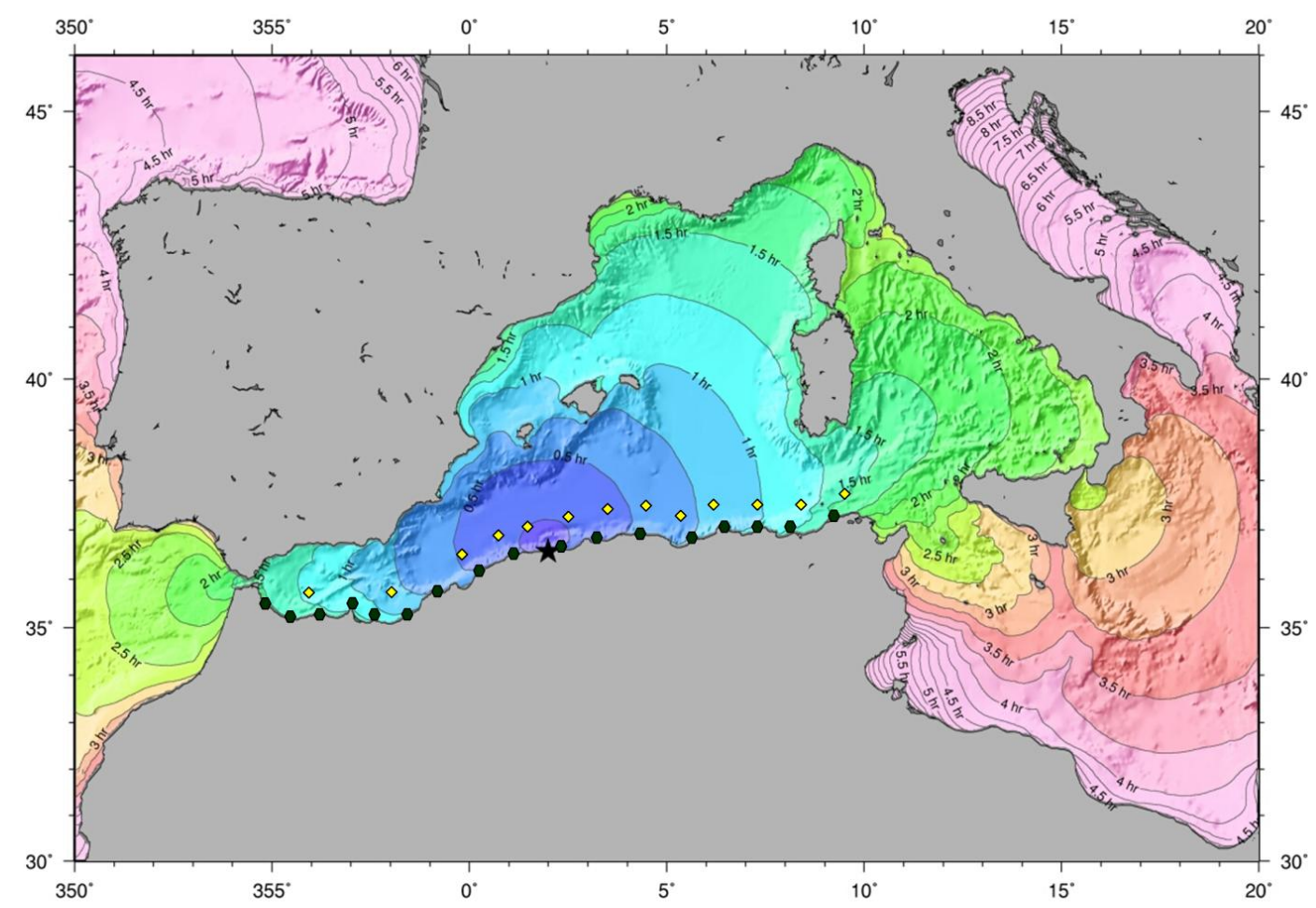

Fig. 8. Recommended monitoring Sea level network for North African coasts of Western Mediterranean; Yellow diamonds are tsunameters located $55 \mathrm{~km}$ offshore, dark green dots are tide gage coastal stations.

These tools would provide event and site specific forecast of tsunami amplitudes for the Western Mediterranean, to assist emergency managers.

Presently the technology does not allow the forecasting for some places along the Spanish coast. The number of tsunameters can be limited to 3 from Gibraltar to the longitude of $1^{\circ} \mathrm{E}$, and thus the total number of required tsunameters can be reduced to 13 . In that zone, the tide gage network with a $40-60 \mathrm{~km}$ spacing is required. 3 supplementary stations must be added, 17 in total along the North Africa coasts. This network would detect the tsunami waves generated by an earthquake in about 5 min (Fig. 3).

In the first step, the tsunameter forecast could be efficient from Alicante to the Northwestern Italian coasts.

The ideal network designed in the paper requires substantial financial supports for equipments, implementation and maintenance. A simpler network that could provide adequate detection capabilities could be composed by only tide gages in the Alboran Sea, and a repartition of tsunameters and tide gages in the other part of the network. This would reduce the number of stations, and consequently the cost of equipment, implementation and maintenance. Nevertheless, the redundancy included in the ideal network would not exist: as one single station will be out of order all the area around that specific station will not be monitored to disseminate an efficient warning in due time.

As mentioned, in Western Mediterranean, most of the earthquakes do not produce large tsunamis. The main pur- pose of the tsunameter network designed in that paper is to provide to emergency managers the current information that immediately after a specific earthquake no tsunami was generated and confirm that the beaches and harbors are safe.

And when the next large tsunami will be generated, this network would provide the only relevant sea level data able to confirm the warning and give the possibility to forecast all the area that could be threatened by the tsunami waves.

\section{Conclusions}

This study determined the architecture, location and spacing of the tsunameter and tide gage networks based on the tsunami generation risk in that region and on the behavior of the tsunami propagation. The method is based on the tsunami travel time estimation, completed by the tsunami beam computed with finite difference codes.

For the southern part of the Western Mediterranean, a network of tsunameters with a spacing of 50 to $90 \mathrm{~km}$ is required along the North Africa coast, located around $50 \mathrm{~km}$ away the shoreline. From West to East, at least 13 tsunameters are required.

This network must be completed with a tide gage network with a spacing of $90 \mathrm{~km}$ in general. In the Alboran Sea, three additional stations are required for an early detection. In total, 17 tide gages are required to monitor the tsunami along the North Africa coast. 
This network would be capable to properly detect and accurately measure any tsunami generated by an earthquake. It will also contribute to a continuous sea level monitoring for all other tsunamis induced by landslides and all storm surges, and, more generally, could also contribute to the intermediate and long term monitoring of sea-level variations in the western Mediterranean region.

Such methodology presented in that paper could be easily applied in other small basins as those in Eastern Mediterranean, in the South-West Pacific and intra-Indonesia seas.

Acknowledgements. The authors wish to thank two anonymous reviewers for their useful and constructive reviews. Travel times were computed using the Tsunami Travel Time software (Geoware) and maps of tsunami heights and travel times were generated using the GMT software (Wessel and Smith, 1995).

Edited by: S. Tinti

Reviewed by: two anonymous referees

\section{References}

Alasset, P.-J., Hébert, H., Maouche, S., Calbini, V., and Meghraoui, M.: The tsunami induced by the 2003 Zemmouri earthquake $(\mathrm{Mw}=6.9$, Algeria): modelling and results, Geophys. J. Int., 166, 213-226, 2006.

ANON: Tsunami Travel Time Charts, for use in the tsunami Warning System National Ocean Survey, Rockville, USA, 53 pp., 1971.

Barrier, E., N. Chamot-Rooke, and G. Giordano: Geodynamic Maps of the Mediterranean, sheet 1, Commission for the Geological Map of the World (CGMW), map at 1:13000 000 scale, 2004.

Déverchère, J., Yelles, K., Domzig, A., Mercier de Lépinay, B., Bouillin, J.-P., Gaullier, V., Bracène, R., Calais, E., Savoye, B., Kherroubi, A., Le Roy, P., Pauc, H., and Dan, G.: Active thrust faulting offshore Boumerdes, Algeria, and its relations to the 2003 Mw 6.9 earthquake, Geophys. Res. Lett. 32, L04311, doi:10.1029/2004GL021646, 2005.

Domzig, A., Yelles, K., Le Roy, C., Déverchère, J., Bouillin, J.P., Bracène, R., Mercier De Lépinay, B., Le Roy, P., Calais, E., Kherroubi, A., Gaullier, V., Savoye, B., and Pauc, H.: Searching for the Africa-Eurasia Miocene boundary offshore western Algeria (MARADJA'03 cruise), C. R. Géoscience, 338, 80-91, doi:10.1016/j.crte.2005.11.009, 2006.

Faccenna, C., Piromallo, C., Crespo-Blanc, A., Jolivet, L., and Rossetti, F.: Lateral slab deformation and the origin of the western Mediterranean arcs, Tectonics, 23, TC1012, doi:10.1029/2002TC001488, 2004.
Gonzalez, F. I., Bernard, E. N., Meinig, C., Eble, M. C., Mofjeld, H. O., and Stalin S.: The NTHMP Tsunameter Network, Developing Tsunami-Resilient Communities, The National Tsunami Hazard Mitigation Program, Springer, 35(1), 25-39, 2005.

Harbi, A., Benouar, D., and Benhallou, H.: Re-appraisal of seismicity and seismotectonics in the north-eastern Algeria Part I: Review of historical seismicity, J. Seismol., 7, 115-136, 2003.

Hébert, H., Heinrich, P., Schindelé, F., and Piatanesi, A.: Far-field simulation of tsunami propagation in the Pacific Ocean: impact on the Marquesas Islands (French Polynesia), J.Geophys. Res., 106, C5, 9161-9177, 2001.

Hébert, H., Schindelé, F., Altinok, Y., Alpar, B., and Gazogliu, C.: Tsunami hazard in the Marmara Sea (Turkey): a numerical approach to discuss active faulting and impact on the Istanbul coastal areas, Mar. Geol., 215, 23-43, 2005.

Henson, J. I., Muller-Karge, F., Wilson, D., Morey, S. I., Maul, G. A., Luther, M., and Kranenburg, C.: Strategic geographic positioning of sea level gauges to aid in early detection of tsunamis in the Intra-Americas Sea, Science of tsunami Hazards, 25, 173207, 2006.

Idn Khaldoun, A. Z. M.: Kitab al Ibar, 1369, Maison du livre Libanais, Beyrut, edited in 1959.

Roger, J. and Hébert, H.: The 1856 Djijelli (Algeria) earthquake: implications for tsunami hazard in Balearic Islands, Nat. Hazards Earth Sys., 8, 721-731, 2008.

Sladen, A., Hébert, H., Schindelé, F., and Reymond, D.: L'aléa tsunami en Polynésie française: apports de la simulation numérique Compte rendu, Geoscience, 339, 303-316, 2007a.

Sladen, A., Hébert, H., and Schindelé, F.: Tsunami hazard in French Polynesia, Nat. Hazards Earth Sys., 7, 195-206, $2007 \mathrm{~b}$.

Shokin, Y., Chubarov, L. B., Novikov, V. A., and Sudabov, A. N.: Calculations of tsunami travel times charts in the Pacific Ocean (models, algorithms, techniques, results), Science of tsunami hazards, 5, 85-114, 1987.

Soloviev, S., Solovieva, O. N., Go, C. N., Kim, K. S., and Shchetnikov, N. A.: Tsunamis in the Mediterranean Sea 2000 B.C. 2000 A.D. Advances in Natural and Technological Hazards Research, Kluwer Academic Publishers, 237 pp., 2000.

Titov, V. V, Mofjeld, H. O., Gonzalez, F. I., and Newman, J. C.: Offshore forecasting of Alaska-Aleutian subduction zone tsunamis in Hawaii, NOAA Tech. Memorandum, ERL PMEL-114, PMEL, Seattle, WA, USA, 22 pp., 1999.

Weissert, T. P.: Tsunami travel time charts for the Caribbean, Science of tsunami hazards, 8, 67-77, 1990.

Yelles-Chaouche, A.: Coastal Algerian earthquakes: a potential risk of tsunamis in Western Mediterranean ? Preliminary investigation, Science of Tsunami Hazards, 9, special issue, 47-55, 1991.

Zetler, B. D.: Travel times of seismic sea waves to Honolulu, Pacific science, 1, 203, 185-188, 1947. 